\title{
In Vivo Identification of Langerhans and Related Dendritic Cells Infected with HIV-1 Subtype E in Vaginal Mucosa of Asymptomatic Patients
}

\author{
Lertlakana Bhoopat, M.D., Lukana Eiangleng, M.T., Sungwal Rugpao, M.D., Sarah S. Frankel, M.D., \\ Drew Weissman, M.D., Ph.D., Suree Lekawanvijit, M.D., Supinda Petchjom, M.D., \\ Paul Thorner, M.D., Ph.D., Tanin Bhoopat, M.D. \\ Departments of Pathology (LB, LE, SL, SP), Obstetrics and Gynecology (SR), and Forensic Medicine (TB), \\ Faculty of Medicine, Chiang Mai University, Chiang Mai, Thailand; Department of Infectious and \\ Parasitic Disease Pathology (SSF), Armed Forces Institute of Pathology, Washington DC; Division of \\ Infectious Diseases (DW), University of Pennsylvania, Philadelphia, Pennsylvania; Division of Pathology \\ (PT), Hospital for Sick Children, and Department of Laboratory Medicine and Pathobiology (PT), \\ University of Toronto, Toronto, Canada
}

In Thailand, the predominant HIV subtype is E, rather than Subtype $B$ as in North America and Europe, and the predominant mode of transmission is heterosexual contact. Subtype $\mathrm{E}$ has the ability to replicate in vitro in Langerhans cells. We hypothesized that this cell type might constitute a reservoir for the HIV virus in vaginal mucosa of asymptomatic carriers. To examine this hypothesis, we compared vaginal tissue histology in HIV-1-seropositive cases with seronegative cases and determined the immunophenotype of HIV-1-infected cells, their numbers, and their distribution in vaginal mucosa. Vaginal biopsies were performed at four different sites from six asymptomatic HIV-1 Subtype E-infected persons and from six seronegative cases at necropsy and examined histologically. Immunophenotyping was performed using immunoperoxidase for Gag p24 HIV, CD3, CD20, CD68, CD1a, S-100 and p55 antigens and by double labeling, combining immunoperoxidase with alkaline phosphatase using pairs of the above antigens. Twenty of twenty-four vaginal biopsies $(\mathbf{8 3 . 3 \%})$ from HIVseropositive cases showed definite inflammation compared to five of twenty-four vaginal necropsies (20.8\%) from HIV-seronegative cases. One third of HIV-seropositive biopsies (8/24) demonstrated p24positive cells in the epithelium, whereas threefourths $(18 / 24)$ of the biopsies revealed p24-positive

Copyright (C) 2001 by The United States and Canadian Academy of Pathology, Inc.

VOL. 14, NO. 12, P. 1263, 2001 Printed in the U.S.A

Date of acceptance: August 28, 2001.

This work was supported partly by The AIDS Research Fund, Ministry of Academic Affairs, Thailand.

Address reprint requests to: Lertlakana Bhoopat, M.D., Department of Pathology, Faculty of Medicine, Chiang Mai University, Chiang Mai 50200,

Thailand; e-mail: lbhoopat@mail.med.cmu.ac.th; fax: 053-217144. cells in the lamina propria. All seropositive patients showed positive cells in at least one biopsy, but not all biopsies contained positive cells. Infected cells were more frequently observed at sites of greater inflammation. The dendritic cell count in HIVseropositive vaginal epithelium was significantly higher than that observed in the seronegative cases $(P=.004)$. The majority of p24-positive cells in the vaginal epithelium were Langerhans cells $(\mathrm{CD} 1 \mathrm{a}+$ I S-100+), whereas in the lamina propria, about half of p24-positive cells were Langerhans-related dendritic cells (p55+ and S-100+) and half were T lymphocytes. In conclusion, the increased propensity for heterosexual transmission of Subtype $\mathbf{E}$ may be related to vaginal inflammation, leading to the accumulation of Langerhans cells and related dendritic cells which, once infected with HIV, can act as a reservoir for further virus transmission.

KEY WORDS: Dendritic cells, Double immunostaining, HIV-1, HIV-1 Subtype E, Langerhans cells, p24, Vaginal mucosa.

Mod Pathol 2001;14(12):1263-1269

Heterosexual transmission is the major route for the spread of new HIV infections worldwide. This is the case in Thailand, where it has been reported that more than $90 \%$ of sexually transmitted viruses are HIV-1 Subtype E $(1,2)$. In contrast, most cases of HIV in the United States and Western Europe are associated with anal intercourse among homosexual men or injection drug users in whom HIV-1 B is the predominant subtype. It has been calculated that heterosexual transmission occurs 5.6 times more frequently per exposure in Thailand compared with in the United States (3). It has therefore 
been suggested that there is an increased propensity for heterosexual transmission of Subtype E, although the same cases reported a higher mean frequency of sexual intercourse and had a higher incidence of sexually transmitted diseases in either partner (4). For instance, a 5.1-fold increase in transmission has been reported in Thai men who give a history of sexually transmitted disease $(3,5,6)$.

The HIV virus has been demonstrated in vitro to have the ability to replicate in epithelial Langerhans cells (LCs), and there is evidence to suggest that Subtype E more readily replicates than Subtype B $(7,8)$. Because these cells may be the first to encounter the virus after mucosal transmission, the ability of the virus to grow in LCs might enhance viral transmission and may explain the epidemiologic findings of increased heterosexual transmission in Thailand and Southeast Asia (8). Using the $\mathrm{SIV} /$ macaque system, Spira et al. (9) reported that the first host cells to be infected were cells of dendritic morphology located in the lamina propria of the vaginal mucosa. SIV-infected cells have also been found in the stratified squamous epithelium of the vagina and ectocervix $(10,11)$. Although this vaginal infection model shows that dendritic cells can serve as a primary target for SIV and be a significant viral reservoir, there is no comparable in vivo evidence for HIV in humans.

We hypothesized that LCs and related histiocytes might constitute a reservoir for HIV Serotype E in mucosa, accounting for increased transmissibility of this serotype. Because HIV in Thailand is predominantly heterosexual in transmission, we examined vaginal mucosal biopsies of seropositive individuals, comparing them with samples from seronegative individuals. Previously, we had noted that there was a greater degree of inflammation in vaginal mucosa of HIV-positive patients from Thailand compared with those in the United States (12), but the level of inflammation in controls was unknown. Therefore, in this study, we determined the degree of inflammation as well as the immunophenotype of the inflammatory cells present. As well, in seropositive cases, HIVpositive cells were identified by immunostaining and were characterized with respect to immunophenotype, number, and distribution within each biopsy.

\section{MATERIALS AND METHODS}

\section{Study Patients}

Six subjects were drawn from a study of 25 couples at Chiang Mai University, Chiang Mai, Thailand. These six represented the HIV-seropositive wives of individuals found to be HIV seropositive at the time of blood donation. They were housewives who were presumably infected by their husbands, and the primary risk factor reported by the hus- bands was contact with a commercial sex worker. Four of six cases reported a history of a sexually transmitted disease. All six subjects showed no abnormal findings on pelvic examination, particularly inflammatory lesions or vaginitis. Cervicovaginal lavage samples from all subjects were negative for the following pathogens: Trichomonas vaginalis, Neisseria gonorrhoeae, Chlamydia trachomatis, Gardnerella vaginalis (bacterial vaginosis), and Candida albicans, using a multiplex PCR and ligase chain reaction as described elsewhere (12). All six patients were shown to be infected with HIV Serotype E (Determine test kit, Abbott Inc., Shiba, Japan); no subjects were receiving anti-retroviral therapy. All had normal hemoglobin concentration and blood clotting time. Vaginal biopsies were taken from the anterior, posterior, and right and left lateral walls, approximately $5 \mathrm{~cm}$ below the posterior fornix. All specimens were taken with informed consent. HIV-seronegative control samples were taken at necropsy from traffic accident victims. Seronegative status was confirmed in all cases.

\section{Light Microscopy}

All specimens were fixed in $10 \%$ buffered formalin, embedded in paraffin, and sectioned at $5 \mu \mathrm{m}$. Sections were stained with hematoxylin and eosin (H\&E) for routine histological examination. Inflammation was graded on a scale of $0-4$ according to the criteria outlined in Table 1.

\section{Immunohistochemistry}

Immunohistochemical staining for HIV gag p24, CD1a, CD3, CD20, CD68, S-100, and p55 (a marker for activated dendritic cells) was performed as described elsewhere (13). For these experiments, working dilutions of the primary antibodies were as follows: 1:5 for HIV gag p24 (monoclonal, DAKO, Carpenteria, CA and from Dr. Sata, National Institute of Health, Tokyo, Japan), 1:4 for CD1a (monoclonal, Immunotech, Brea, CA), 1:150 for CD3 (polyclonal, DAKO), 1:20 for CD20

TABLE 1. Pathological Scale for Grading Inflammation in Vaginal Mucosa

\begin{tabular}{|c|c|c|}
\hline $\begin{array}{l}\text { Rating } \\
\text { No. }\end{array}$ & $\begin{array}{l}\text { Rating } \\
\text { Label }\end{array}$ & Description \\
\hline 0 & Normal & \\
\hline 1 & Minimal & $\begin{array}{l}\text { Scattered lymphocytes within lamina propria above } \\
\text { that usually observed in normal tissue. }\end{array}$ \\
\hline 2 & Mild & $\begin{array}{l}\text { Small clusters of lymphocytes within epithelium } \\
\text { and lamina propria. }\end{array}$ \\
\hline 3 & Moderate & $\begin{array}{l}\text { More extensive lymphocytic infiltration of lamina } \\
\text { propria and epithelium, with perivascular } \\
\text { accumulation, focal capillary extension into } \\
\text { epithelium, and focal breakdown of basal layer of } \\
\text { epithelium. }\end{array}$ \\
\hline 4 & Severe & $\begin{array}{l}\text { Diffuse lymphocytic infiltrate in lamina propria and } \\
\text { epithelium, capillary extension into epithelium, } \\
\text { disrupted epithelial basal layer. }\end{array}$ \\
\hline
\end{tabular}


(monoclonal, DAKO), 1:50 for CD68 (monoclonal, DAKO), 1:200 for S-100 (polyclonal, DAKO), and 1:100 for p55 (monoclonal, DAKO). Sections cut at $5 \mu \mathrm{m}$ were subjected to microwave pretreatment for antigen retrieval. Overnight incubation was used for p24, CD1a, CD68, and p55, whereas other antibodies were applied for one hour. The secondary antibody was biotinylated horse anti-mouse antibody (Vector, Burlingame, CA), followed by avidin-biotin-peroxidase complex (Vector) and 3,3'-diaminobenzidine as the chromogen.

A double-labeling technique was performed based on a method described elsewhere (14) to determine the identity of HIV-infected cells. The biopsy from each case with the highest count of p24-positive cells was used for double labeling. The first primary antibody was HIV gag p24 stained as described above. After washing, a second primary monoclonal antibody (from those listed above) was applied, followed by an alkaline phosphatase-conjugated goat anti-mouse IgG (Sigma, Singapore) for 30 min. The slides were then washed in $\mathrm{NaHCO}_{3}$ (pH8.3) for $10 \mathrm{~min}$, followed by a 40-min incubation period with the alkaline phosphatase substrate composed of 5-mg fast BBN salt, $100 \mu \mathrm{l}$ dimethylformamide, $1000 \mu \mathrm{l}$ naphtholASMX alkaline phosphate solution (Sigma), $5 \mu$ l levamisole $(1.0 \mathrm{M})$, and $4.9 \mathrm{~mL} 0.1 \mathrm{~m}$ Tris buffer ( $\mathrm{pH}$ 8.2). The slides were then washed in tap water for 10 min and mounted. Controls included reversal of the chromogens for reproducibility and omission of the second primary monoclonal antibody to demonstrate that the second labeling system did not react with antibodies already present as part of the first stage.

\section{Cell Counts}

The number of Langerhans and dendritic cells detected by S-100 immunostaining was determined by counting the number of positive cells per 100 basal epithelial cells at $250 \times$ magnification by three pathologists blinded to the patients' HIV serostatus. Although all biopsies were stained for S-100, CD1a, and p55 to confirm the identity of LCs and related histiocytes, S-100 immunostaining provided the most consistent staining and was therefore used for cell counting. Separate counts were performed for epithelium and the lamina propria. The value obtained was the average number of positive cells in the 4 biopsies from each case. The same approach was used to quantitate the number of HIV gag p24positive cells.

\section{RESULTS}

\section{Vaginal Histology}

HIV-seropositive tissues overall showed more inflammation than seronegative controls (Fig. 1). Cer-

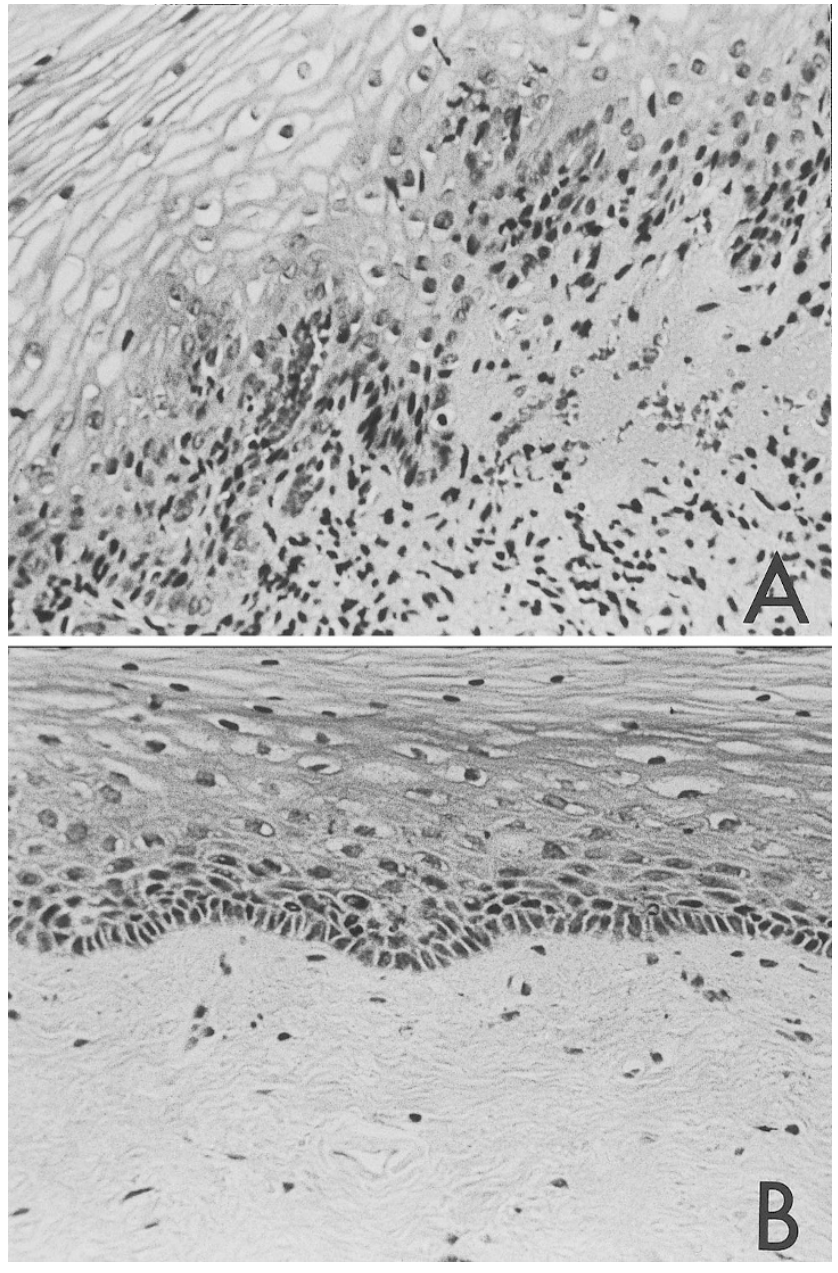

FIGURE 1. Histologic appearance of vaginal mucosa. The degree of inflammation varied from site to site in individual patients but tended to be more severe in HIV-positive individuals. Illustrated here are A, the more severe degree of inflammation in an asymptomatic seropositive case showing diffuse lymphocytic infiltration of the lamina propria with extension into the epithelium and $\mathbf{B}$, the opposite end of the spectrum in a seronegative case showing no inflammation (both $\mathrm{H} \& \mathrm{E}, 200 \times$ ).

tain biopsies showed a psoriasiform pattern of inflammation, with blood vessel extension into the epithelial layer. Twenty of twenty-four vaginal biopsies (83.3\%) from HIV-seropositive cases revealed inflammation Grade 2 and higher (see Table 2 ), whereas only five of twenty-four $(20.8 \%)$ specimens from HIV-seronegative cases demonstrated

TABLE 2. Inflammation in Seropositive vs. Seronegative Vaginal Tissue Specimens

\begin{tabular}{cll}
\hline $\begin{array}{c}\text { Grade of } \\
\text { Inflammation }\end{array}$ & \multicolumn{2}{c}{ No. of Specimens $(n=24)$} \\
\hline & HIV Seropositive & HIV Seronegative \\
Biopsies & Biopsies \\
0 & $0 \quad$ (from 3 patients) \\
1 & 4 (from 2 patients) & 12 (from 4 patients) \\
2 & 11 (from 4 patients) & 3 (from 2 patients) \\
3 & 6 (from 3 patients) & 2 (from 1 patient) \\
4 & 3 (from 2 patients) & 0 \\
\hline
\end{tabular}


the same degree of inflammation and the rest showed minimal or no inflammation.

\section{Concentration of Langerhans and Dendritic Cells in Vaginal Mucosa}

The values for the number of Langerhans and dendritic cells in the vaginal epithelial layer and lamina propria are shown in Table 3 . The mean number of Langerhans cells in the epithelium was 18 (range of 9-30) in the HIV-seropositive and 5.33 (range of 3-9) in the HIV-seronegative cases, which was a statistically significant difference, with a $P$ value of .004 by Mann-Whitney $U$ test. The mean number of dendritic cells in lamina propria was 15.83 (range of 9-27) in the HIV-seropositive subjects and 10 (range of 6-13) in the HIV-seronegative subjects. This difference was not statistically significant ( $P=.104$ by Mann-Whitney $U$ test).

\section{Concentration of p24-Bearing Cells in Vaginal Mucosa}

Eight of 24 biopsies demonstrated cells positive for intracellular p24 in the range of 1-3 cells (mean of 2 cells) per 100 basal epithelial cells while in the lamina propria, 18 of 24 biopsies showed p24positive cells in the range of $1-10$ cells (mean of 7.5 cells) per 100 basal epithelial cells. Considering all six cases, at least one biopsy site revealed p24positive cells in the lamina propria, but two out of six cases showed no p24-positive cells in the epithelium. In addition, p24-positive cells were more numerous in areas of greater inflammation. In the epithelium, p24-positive cells had a dendritic morphology and were located just above and between the basal cells, whereas the positive cells in the lamina propria were located within $100 \mu \mathrm{m}$ of the epithelium and many were adjacent to the basement membrane of the epithelium, within papillae, and around blood vessels. Up to $40 \%$ of positive cells in the lamina propria showed dendritic morphology (Fig. 2A). The remainder were mononuclear cells (lymphocytes and histiocytes). All seronegative biopsies were negative for p24 by immunostaining.
Distribution and Reactivity of Various Markers in Vaginal Mucosa

The majority of inflammatory cells in the epithelium were dendritic cells by morphology and were positive by immunoperoxidase for one or more of S-100, CD1a, and p55, as shown in Table 4. Smaller numbers of T-lymphocytes (CD3 positive) and a few non-Langerhans histiocytes (CD68 positive) were also present. $T$ lymphocytes made up the highest proportion of cells in the lamina propria, although frequent dendritic cells and other macrophages were also detected. Only a few B lymphocytes positive for CD20 were observed in the lamina propria.

\section{Identification of p24-Bearing Cells by \\ Double Immunostaining}

The majority of p24-positive cells in the epithelium were also positive for CD1a (Fig. 2B-C), S-100, and p55, whereas S- $100^{+} / \mathrm{p} 55^{+}$dendritic cells made up about half of the p24-positive cells in the lamina propria. Scattered p24-positive cells had the appearance of Warthin-Finkeldy-type giant cells; these cells expressed S-100 and p55. CD1a-positive cells were found mostly in the epithelium, with only few positive cells in the papillae of the lamina propria. $\mathrm{CD}^{+}$lymphocytes comprised about $50 \%$ of the p24-positive cells in the lamina propria, but these were not seen in the epithelium. Some $\mathrm{CD} 8^{+} / \mathrm{p} 24^{+}$cells were also identified in both the epithelium and the lamina propria. Considering the total population of cells present, about $40 \%$ of the LCs in the epithelium were p24-positive, whereas in the lamina propria, about $60 \%$ of the LCs and related histiocytes were positive but only about $30 \%$ of the $\mathrm{T}$ lymphocytes were positive.

\section{DISCUSSION}

In this study, we tested the hypothesis that Langerhans and related histiocytes might constitute a reservoir for HIV Subtype E in vaginal mucosa. Previous studies had shown increased transmissibility of this subtype by heterosexual contact. We rea-

TABLE 3. Dendritic Cell Count in Vaginal Mucosa in HIV-Seropositive versus -Seronegative Cases

\begin{tabular}{|c|c|c|c|c|}
\hline \multirow{2}{*}{ Case No. } & \multicolumn{2}{|c|}{ HIV Seropositive } & \multicolumn{2}{|c|}{ HIV Seronegative } \\
\hline & Epithelium & Lamina Propria & Epithelium & Lamina Propria \\
\hline 1 & 21 & 18 & 9 & 11 \\
\hline 2 & 30 & 12 & 3 & 12 \\
\hline 3 & 9 & 9 & 5 & 6 \\
\hline 4 & 12 & 11 & 4 & 9 \\
\hline 5 & 20 & 27 & 6 & 13 \\
\hline 6 & 16 & 18 & 5 & 9 \\
\hline Mean & 18 & 15.83 & 5.33 & 10 \\
\hline
\end{tabular}

Values represent the average number of dendritic cells per 100 basal cells from four different locations for each case, as assessed by S-100 immunostaining. 


\begin{tabular}{|c|c|c|c|c|c|}
\hline \multirow{2}{*}{ Case No. } & \multicolumn{5}{|c|}{ No. of Positive Cells in the Epithelium/Lamina Propria* } \\
\hline & CD1a & S-100 & p55 & CD68 & CD3 \\
\hline 1 & $8 / 0$ & $18 / 1$ & $1 / 3$ & $6 / 7$ & $8 / 10$ \\
\hline 2 & $9 / 0$ & $20 / 8$ & $2 / 10$ & $5 / 9$ & $5 / 11$ \\
\hline 3 & $7 / 1$ & $3 / 7$ & $0 / 3$ & $1 / 4$ & $7 / 13$ \\
\hline 4 & $8 / 0$ & $1 / 1$ & $1 / 7$ & $1 / 6$ & $3 / 15$ \\
\hline 5 & $5 / 0$ & $8 / 4$ & $1 / 5$ & $2 / 5$ & $1 / 10$ \\
\hline 6 & $6 / 1$ & $13 / 6$ & $3 / 11$ & $1 / 8$ & $1 / 15$ \\
\hline
\end{tabular}

* Determined by the number of immunopositive cells per 100 basal cells of the epithelium.

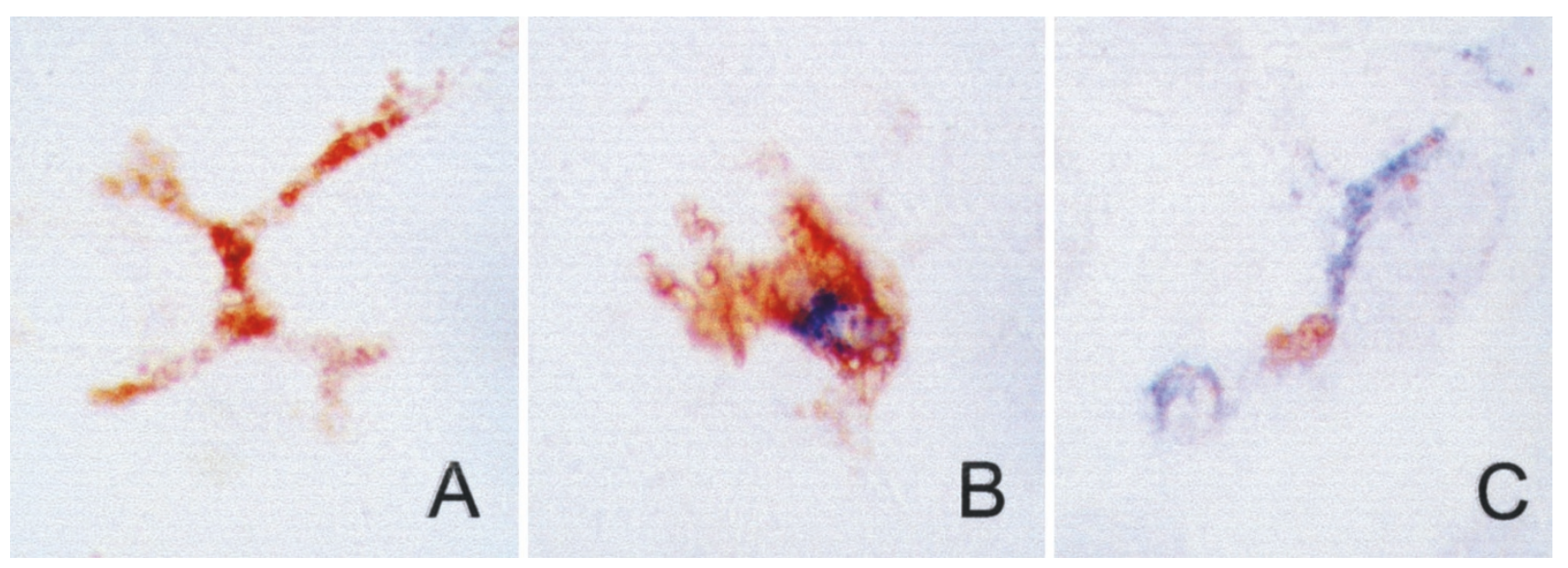

FIGURE 2. Immunohistochemical detection of HIV-1 gag protein p24 in seropositive vaginal mucosa. A, p24-positive cell showing dendritic morphology (immunoperoxidase with 3,3'-diaminobenzidine, 1000×). B, double immunostaining showing Langerhans cells positive for CD1a (brown) containing p24 gag protein in the cytoplasm (blue; immunoperoxidase for CD1a combined with alkaline phosphatase for p24; $1000 \times$ ). C, reversal of the chromogens showing, this time, Langerhans cells positive for CD1a (blue) with p24 gag protein in the cytoplasm (brown; immunoperoxidase for p24 combined with alkaline phosphatase for CD1a; $1000 \times$ );

soned that a vaginal mucosal reservoir with infected Langerhans cells might help explain this observation. We tested this hypothesis by direct examination of vaginal mucosal biopsies, an approach not previously reported. We noted that there are HIV-positive cells in both the vaginal epithelium and lamina propria. Increased numbers are associated with increased degrees of inflammation. HIV-positive cells in the vaginal epithelium are mainly Langerhans cells, whereas those in the lamina propria are mainly Langerhans-related dendritic cells and $\mathrm{T}$ lymphocytes.

Two main findings emerge from our study. First, vaginal mucosa of seropositive asymptomatic patients shows a greater degree of chronic inflammation than seronegative controls ( $83 \%$ versus $21 \%$ ). Furthermore, this was the result of increased numbers of LCs and related dendritic cells, in addition to lymphocytes. There was a significant increase in the number of LCs in vaginal epithelium of HIVinfected individuals compared with in the noninfected controls. Interestingly, similar study using cervical mucosa found the opposite result (15) with significantly fewer LCs in HIV-positive patients compared with seronegative controls. The absolute numbers of cells in this study are lower, with only 1 and 2 LCs/100 basal cells in the HIV-positive and negative groups, respectively, compared with 18 and $5 \mathrm{LCs} / 100$ basal cells in the same two groups in our study. Perhaps this reflects the patient population (European versus Thai) or the site examined (cervix versus vagina). Another possible factor may be that the numbers of LCs in symptomatic individuals were found to be lower than in those who are asymptomatic, and in our study we included only asymptomatic patients. This may not be a factor, however, because other studies using skin biopsies have refuted any association between LC density and stage of HIV clinical disease (16).

We also observed that the more intense the inflammation, the greater the number of HIV-positive cells that were present. One possible explanation is that inflammation predisposes the vaginal mucosa to be an efficient host for infection with the virus. It has been documented that a history of sexually transmitted diseases, both ulcerating and nonulcerating, as well as abnormal vaginal flora and bacterial vaginosis, have been associated with increased risk of HIV infection (17-21). In our study, four out of six seropositive cases reported a history of a sexually transmitted disease, although no pathogens could be identified at the time of biopsy in 
cervicovaginal lavage samples. Not all potential pathogens were tested for, including herpes simplex and human papilloma virus (HPV). HIVseropositive women are more frequently infected by HPV than are HIV-seronegative controls (22-24). We have observed similar inflammation in HPVinfected vaginal tissues (unpublished data), and HPV may be one of the possible agents that causes the vaginal mucosal inflammation in HIV-positive patients. We also noted that infiltration of vaginal tissue by inflammatory cells was associated with breaks in the basement membrane. Loss of physical integrity of the mucosal barriers, together with an increase in the number of infected cells, could enhance the risk of heterosexual transmission.

The second main point from our study relates to the location and identity of the cells infected with HIV. From double immunostaining studies, we found that there are different subsets of HIV-1 Subtype E-infected cells. The majority of HIV-infected cells in the epithelium were Langerhans cells that expressed CD1a, S-100, and p55 and were located just above and in between the basal cells, with a few cells migrating into blood vessels of the papillae of the lamina propria. Although most of the cell infiltrate in the lamina propria consisted of $\mathrm{T}$ lymphocytes, the HIV-infected cells in this region were roughly an equal mixture of $\mathrm{T}$ cells and cells determined by morphology and immunophenotype to be Langerhans-related dendritic cells. These cells were $\mathrm{S}-100+$ and p55+, a pattern that is typically associated with paracortical interdigitating dendritic cells and Langerhans cells $(25,26)$. Scattered HIV-infected cells had a Warthin-Finkeldy-type giant cell morphology. These cells were also positive for S-100 and p55, implying a relation to dendritic cells. A similar observation was made in tonsils from HIV patients, in whom these multinucleated cells were positive for p24, S-100, and CD68 and negative for CD1a, CD21, and EBV. The authors concluded that these cells are a subtype of histiocyte related to LCs and dendritic cells, resulting from HIV infection and not EBV (27).

In terms of the numbers of infected cells, we found that $40-60 \%$ of the LCs and related histiocytes present in the biopsies were infected with HIV, whereas only $30 \%$ of the $\mathrm{T}$ cells were. This result suggests that LCs are more readily infected with HIV at least in the early stages of the disease, since our patients were all asymptomatic. A similar study was done on skin biopsies from HIV-infected patients and it was also found that one third to one half of the LCs present were infected with HIV as determined by p24 immunostaining (28). Another study using skin biopsies found that only cells infected with HIV were LCs and not T lymphocytes (29). This result contrasts with ours, in which infected T cells comprised $\sim 50 \%$ of the infected cells in the lamina propria. Whether this reflects a difference in viral subtype or a difference in the site of the biopsy is unknown. We did not have available for comparison biopsies from other mucocutaneous sites, such as skin, cervix, oral, or rectal mucosa. Such specimens would be valuable in determining the number of HIV-infected cells and the number of Langerhans cells present. In this way, one could confirm whether there is a particular susceptibility of vaginal mucosa to HIV Subtype E or an increased susceptibility to infection because of increased numbers of Langerhans cells in a setting of inflammation.

A previous study compared vaginal biopsies from patients infected with Subtype E and Subtype B (12). Those samples were analyzed using a PCR-based methodology (rather than immunohistochemistry) in which lymphocytes and Langerhans cells were not assessed separately; hence, a direct comparison with the present study is not possible. Nevertheless, in that study, vaginal biopsies from Thai women showed on average a greater degree of inflammation and a higher HIV load in vaginal epithelium when compared with United States women infected with Subtype B. These results suggest that vaginal mucosa is more easily infected by Subtype E than Subtype B and that Subtype $\mathrm{E}$ infection is more often associated with inflammation. It would be informative to analyze additional samples from Subtype B infection using the approach in this paper to immunophenotype, localize, and quantitate the HIV-infected cells. In this way, it could be determined whether there are increased numbers of Langerhans cells in Subtype E compared with in Subtype B and to determine what percentage of this cell population is infected in each subtype.

Trafficking of lymphocytes and dendritic cells has been well defined. From vaginal mucosa, primarily Langerhans and dendritic cells but also lymphocytes migrate into the afferent lymphatics, where they enter the lymph nodes through the subcapsular sinus and traverse toward the T-cell areas in the paracortical regions. Whereas antigen-presenting cells terminate here and present antigens, infected mononuclear cells and free virus can leave through the efferent lymphatics and disseminate widely. It might be expected that any factor that results in increased antigen presentation at the time of transmission, for example, concomitant inflammation as we found in this study, could result in more efficient viral spread within an infected individual. However, the presence of increased numbers of antigen-presenting cells could have another consequence. Our study has shown that these cells are one of the main cell types infected with HIV Serotype $\mathrm{E}$ in vaginal mucosa and as such may serve as a viral reservoir in asymptomatic patients. Concomitant inflammation of the mucosa may facilitate the spread of the cells and/or free virus to a 
sexual partner, in keeping with the increased transmissibility of Serotype E that has been reported by heterosexual contact. It has been also shown in vitro that LCs are efficiently infected with HIV in the presence of CD40 ligand, which can be present on T cells (30). Hence the combined presence of LCs and $\mathrm{T}$ cells that we observed in the vaginal mucosal biopsies may also provide a setting for increased transmission of HIV. In vivo studies such as this one allow examination at the tissue and cellular level to further our understanding of the mechanism of HIV transmission. This is needed to design appropriate therapies as well as prophylactic vaccines directed at the etiologic agent.

\section{Acknowledgment: The authors thank Ms. Wattana- porn Wisedmongkol for editorial assistance.}

\section{REFERENCES}

1. Weniger B. Experience from HIV incidence cohorts in Thailand: implications for HIV vaccine efficacy trials. AIDS 1994; 8:1007-10.

2. Weniger B, Takebe Y, Ou C, Yamazaki S. The molecular epidemiology of HIV in Asia. AIDS 1994;8:S13-28.

3. Mastro T, Satten G, Nopkesorn T, Sangkharomya S, Longini I. Probability of female-to-male transmission of HIV-1 in Thailand. Lancet 1994;343:204-7.

4. Kunanusont C, Foy H, Kreiss J, Rerks-Ngarm S, Phanuphak P, Raktham S, et al. HIV-1 subtypes and male-to-female transmission in Thailand. Lancet 1995;345:1078-83.

5. Mastro T, de Vincenzi I. Probabilities of sexual HIV-1 transmission. AIDS 1996;10:S75-82.

6. Satten G, Mastro T, Longini I. Modelling, the female-to-male per-act HIV transmission probability in an emerging epidemic in Asia. Stat Med 1994;13:2097-106.

7. Rappersberger K, Gartner S, Schenk P, Stingl G, Groh V, Tschachler E, et al. Langerhans' cells are an actual site of HIV-1 replication. Intervirology 1988;29:185-94.

8. Soto-Ramirez L, Renjifo B, McLane M, Marlink R, O'Hara C, Sutthent R, et al. HIV-1 Langerhans' cell tropism associated with heterosexual transmission of HIV. Science 1996;271: 1291-3.

9. Spira A, Marx P, Patterson B, Mahoney J, Koup R, Wolinsky $\mathrm{S}$, et al. Cellular targets of infection and route of viral dissemination after an intravaginal inoculation of simian immunodeficiency virus into Rhesus macaques. J Exp Med 1996;183:215-25.

10. Hu J, Pope M, Brown C, O’Doherty U, Miller C. Immunophenotypic characterization of simian immunodeficiency virusinfected dendritic cells in the cervix, vagina, and draining lymph nodes of rhesus macaques. Lab Invest 1998;78:435-51.

11. Miller $\mathrm{C}, \mathrm{Hu} \mathrm{J}$. T cell-tropic simian immunodeficiency virus (SIV) and simian-human immunodeficiency viruses are readily transmitted by vaginal inoculation of Rhesus macaques, and Langerhans' cells of the female genital tract are infected with SIV. J Infect Dis 1999;179:S413-7.

12. Cohn M, Frankel S, Rugpao S, Young M, Willett G, Tovanabutra S, et al. Chronic inflammation with increased human immunodeficiency virus (HIV) RNA expression in the vaginal epithelium of HIV-infected Thai women. J Infect Dis 2001;184:410-7.

13. Bhoopat L, Patanasakpinyo C, Yanaranop M, Bhoopat T. Clinico-immunopathological alterations of lymph nodes from human immunodeficiency virus-infected patients in northern Thailand. Asian Pac J Allergy Immunol 1999;17:85-92.

14. Hofman F, Modlin R, Bhoopat L, Taylor C. Distribution of cells bearing the Tac antigen during ontogeny of human lymphoid tissue. J Immunol 1985;134:3751-5.

15. Spinillo A, Tenti P, Zappatore R, De Seta F, Silini E, Guaschino S. Langerhans' cell counts and cervical intraepithelial neoplasia in women with human immunodeficiency virus infection. Gynecol Oncol 1993;48:210-3.

16. Nandwani R, Gazzard B, Barton S, Hawkins D, Zemelman V, Staughton R. Does HIV disease progression influence epidermal Langerhans cell density? Br J Dermatol 1996;134: 1087-92.

17. Wasserheit J. Epidemiological synergy. Interrelationships between human immunodeficiency virus infection and other sexually transmission diseases. Sex Transm Dis 1992;19:61-77.

18. Laga M, Manoka A, Kivuvu M, Malele B, Tuliza M, Nzila N, et al. Non-ulcerative sexually transmitted diseases as risk factors for HIV-1 transmission in women: results from a cohort study. AIDS 1993;7:95-102.

19. Cohen C, Duerr A, Pruithithada N, Rugpao S, Hillier S, Garcia $\mathrm{P}$, et al. Bacterial vaginosis and HIV seroprevalence among female commercial sex workers in Chiang Mai, Thailand. AIDS 1995;9:1093-7.

20. Boily M, Anderson R. Human immunodeficiency virus transmission and the role of other sexually transmitted diseases. Measures of association and study design. Sex Transm Dis 1996;23:312-32.

21. Sewankambo N, Gray R, Wawer M, Paxton L, McNaim D, Wabwire-Mangen F, et al. HIV-1 infection associated with abnormal vaginal flora morphology and bacterial vaginosis. Lancet 1997;350:546-50.

22. Ho G, Burk R, Fleming I, Klein R. Risk of genital human papillomavirus infection in women with human immunodeficiency virus-induced immunosuppression. Int J Cancer 1994;56:788-92.

23. Vernon S, Holmes K, Reeves W. Human papillomavirus infection and associated disease in persons infected with human immunodeficiency virus. Clin Infect Dis 1995;21:S121-4.

24. Chopa K, Tyring S. The impact of the human immunodeficiency virus on the human papillomavirus epidemic. Arch Dermatol 1997;133:629-33.

25. Pinkus G, Pinkus J, Langhoff E, Matsumura F, Yamashiro S, Mosialos G, et al. Fascin, a sensitive new marker for ReedSternberg cells of Hodgkin's disease. Evidence for a dendritic or B cell derivation? Am J Pathol 1997;150:543-62.

26. Wenig B, Thompson L, Frankel S, Burke A, Abbondanzo S, Sesterhenn I, et al. Lymphoid changes of the nasopharyngeal and palatine tonsils that are indicative of human immunodeficiency virus infection. A clinicopathologic study of 12 cases. Am J Surg Pathol 1996;20:572-87.

27. Kapadia S, Wiley C, Soontornniyomkij V, Wang G, Swerdlow S. HIV-associated Waldeyer's ring lymphoid hyperplasias: characterization of multinucleated giant cells and the role of Epstein-Barr virus. Hum Pathol 1999;30:1383-8.

28. Compton C, Kupper T, Nadire K. HIV-infected Langerhans cells constitute a significant proportion of the epidermal Langerhans cell population throughout the course of HIV disease. J Invest Dermatol 1996;107:822-6.

29. Henry M, Uthman A, Ballaun C, Stingl G, Tschachler E. Epidermal Langerhans cells of AIDS patients express HIV-1 regulatory and structural genes. J Invest Dermatol 1994;103:593-6.

30. Kawamura T, Qualbani M, Thomas E, Orenstein J, Blauvelt A. Low levels of productive HIV infection in Langerhans cell-like dendritic cells differentiated in the presence of TGFbetal and increased viral replication with CD40 ligandinduced maturation. Eur J Immunol 2001;31:360-8. 